\title{
Fluxes of Biomass and Essential Polyunsaturated Fatty Acids from Water to Land via Chironomid Emergence from a Mountain Lake
}

\author{
E. V. Borisova ${ }^{a}$, O. N. Makhutova ${ }^{a, b}$, M. I. Gladyshev ${ }^{a, b}$, and N. N. Sushchik ${ }^{a, b}$ \\ ${ }^{a}$ Siberian Federal University, pr. Svobodny 79, Krasnoyarsk, 660041 Russia \\ ${ }^{b}$ Institute of Biophysics, Siberian Branch, Russian Academy of Sciences, Akademgorodok 50/50, Krasnoyarsk, 660036 Russia \\ e-mail: shelob@mail.ru,makhutova@ibp.krasn.ru,glad@ibp.ru,labehe@ibp.ru \\ Received October 24, 2015; in final form, December 07, 2015
}

\begin{abstract}
The taxonomic composition, seasonal dynamics, and emergence intensity of chironomid adults (the Chironomidae family) emerging from the Oiskoe mountain oligotrophic lake (Western Sayan, Southern Siberia) have been established. The value of the annual emergence of chironomid adults average $0.42 \mathrm{~g}$ wet weight $\mathrm{m}^{-2}$ in the lake area and approach the value of potential emergence, which is calculated based on the estimate of zoobenthos secondary production. For the first time the fatty-acid composition and contents of essential omega-3 polyunsaturated fatty acids (PUFAs) are compared between the larvae and adult stages of chironomids. The PUFA content per wet weight unit in adults is more than 7 times higher than that in larvae. The PUFA flux per lake area unit resulting from the chironomid emergence amounted to $1.752 \mathrm{mg} \mathrm{m}^{-2} \mathrm{y}^{-1}$, which is over 10 times lower than the global estimate for the emergence of amphibiotic insects. Calculations show that the PUFA flux brought with the chironomid emergence per land unit of the studied mountain territory is very low when compared to that for other landscapes, with the exception of the shoreline part of the territory with a width of $15 \mathrm{~m}$, in which the PUFA flux is comparable to that in productive landscapes.
\end{abstract}

Keywords: amphibiotic insect emergence, Chironomidae, mountain landscape, polyunsaturated fatty acids, biogenic fluxes from water to land

DOI: $10.1134 /$ S199542551604003X

\section{INTRODUCTION}

Currently, the transfer of the total organic matter and nutrients through the water-land boundary is considered one of the key processes of interaction between aquatic and terrestrial ecosystems in different ecological landscapes (Baxter et al., 2005; Richardson et al., 2010). According to the global assessments and reviews of the literature, the emergence of amphibiotic insect images is the largest part of the total flux of organic matter that is produced in freshwater ecosystems and enters terrestrial food webs (Vander Zanden and Gratton, 2011; Bartels et al., 2012). The biomass of emerging aquatic insects can account for a significant share in the diet of terrestrial consumers that live in the shoreline zone, such as arthropods, lizards, bats, and insectivorous birds (Nakano and Murakami, 2001; Sabo and Power, 2002; Reimer et al., 2010.; Stenroth et al., 2015).

Along with a significant quantitative contribution to the flux of organic carbon and energy, imagees of emerging insects are also a source of essential biochemical food components for terrestrial animals (Gladyshev et al., 2009; 2013). These essential biochemical components are long-chain polyunsaturated fatty acids of the $\omega 3$ family. As is known, these substances, namely, eicosapentaenoic acid (20:5n-3, EPA) and docosahexaenoic acid (22:6n-3, DHA), cannot be synthesized de novo, but are necessary for the functioning of the cardiovascular, nervous, and immune systems in consumers of different levels of organization, including humans (Lands, 2009). Among all organisms, only some algae species are able to synthesize large amounts of EPA and DHA (diatoms, dinophytes, and cryptophytes), so aquatic ecosystems play a unique role in the Biosphere, being the main source of EPA and DHA for most animals, among which there are omnivorous land dwellers, including humans (Gladyshev et al., 2009).

As is known, terrestrial insects do not contain or have very small quantities of long chain $\omega 3$ EPA and DHA in biomass (Stanley-Samuelson et al., 1988.; Fontaneto et al., 2011; Rumpold and Schluter, 2013). In contrast, almost all studied amphibiotic insects are characterized by a high content of EPA, which they accumulate at the larval stage, obtaining it from microalgae through water trophic chains (Gladyshev et al., 2009; 2011a; Sushchik et al., 2013). 
We have estimated for the first time the global EPA and DHA fluxes from aquatic to terrestrial ecosystems (Gladyshev et al., 2009) and found that the emergence of the adult amphibiotic insects from internal water bodies and estuaries to the land is one of the main fluxes in the global export of these essential biochemical components to the land that is $240 \times 10^{6} \mathrm{~kg} /$ year. However, it is obvious that the generalized global estimates do not make allowance for the significant variability of different landscapes (biomes) and, accordingly, the specificity of EPA and DHA fluxes to the land. Therefore, global preliminary calculations should be supplemented and verified by practical estimates of PUFA fluxes to the land in different biomes and landscapes.

Most studies that have identified the production of benthic communities and fluxes of matter brought with the emergence of amphibiotic insects were conducted at water flows, i.e., rivers and streams (Bartels et al., 2012; Muehlbauer et al., 2014). In connection with the morphological features of water flows (waterlevel fluctuations and lack of a clear shoreline), the characteristics of flows that link aquatic and terrestrial ecosystems are often expressed per unit area of a water flow rather than per unit area of an adjacent land (Vander Zanden and Gratton, 2011). However, due to the much larger area of the water surface, the potential of lenthic water systems as a source of biomass of amphibiotic insects arriving per unit of land area can prove to be much larger in comparison with that of streams and rivers (Gratton and Vander Zanden, 2009). Moreover, the estimates of the emergence of amphibiotic insects from lenthic ecosystems are few; the vast majority of them were made in low-lying landscapes, namely, in wetlands of temperate and subtropical climate or in tundra (MacKenzie and Kaster, 2004; MacKenzie, 2005; Dreyer et al., 2012). In such habitats, prevalence is held by temporary reservoirs, which, according to some estimates, are less productive than constant ones (Lundstrom et al., 2010). However, landscapes such as mountain and foothill areas, where constant lenthic systems (lakes) are prevalent, remain almost unstudied.

According to the studies of many mountain ecosystems, especially rivers and streams, the basis of the production of benthic communities is made up larvae of insects belonging the Diptera order of the $\mathrm{Chi}$ fomida family (Maiolini et al., 2006; Scheibler et al., 2014). Similarly to the communities of mountain streams, the benthos of some mountain lakes is also represented mainly by the chironomid fauna. Therefore, in Oiskoe Lake, which is a large alpine reservoir located in a mountain valley of the Western Sayan Mountains (Southern Siberia, Russia), the contribution of chironomids to the macrozoobenthos production reaches $68 \%$ (Zuev et al., 2012).

Thus, the purpose of this study was to determine the export of total organic matter and essential EPA and DHA to the land via the emergence of amphibiotic insects, namely chironomids of the Chironomidae family, from the Oiskoe Mountain Lake (the Western Sayan Mountain Range). The following specific objectives were formulated: (a) Determining the seasonal dynamics of the daily emergence of chironomid adults and estimating the total annual emergence of this group from a lake area unit; (b) defining the boundaries of the adjacent land area that corresponds to the potential range of the expansion of chironomid adults and estimating the export of the chironomid biomass per unit of land area; and (c) making a comparative analysis of the content of EPA and DHA in chironomid larvae and adults and determining the export of EPA and DHA from a water area unit to a land area unit in the studied region.

\section{MATERIALS AND METHODS}

\section{The Studied Area}

The studies were carried out in Oiskoe Lake $\left(52^{\circ} 50^{\prime} 28 \mathrm{~N}, 93^{\circ} 14^{\prime} 46^{\prime \prime} \mathrm{E}\right)$, which is located in the Western Sayan Mountain Range at an altitude of 1416 $\mathrm{m}$ above sea level. The characteristics of the reservoir and surrounding area were described in detail in the wrks (Ivanova et al., 2014; Anishchenko et al., 2015). In short, the climate and vegetation of the studied area correspond to the mountain taiga belt. The lake is in a mountain valley and has its own catchment area (Fig. 1). The open water period at the lake lasts from late May to the first or second decade of October. The maximum depth of the lake is $21 \mathrm{~m}$, the average depth is $8 \mathrm{~m}$, and the water surface area is $522121 \mathrm{sq}$. $\mathrm{m}$. The lake is oligotrophic and characterized by low amounts of biomass and phytoplankton production. However, the main contribution to the gross primary production is made by higher aquatic plants that grow in the vast littoral part of the lake (Ivanova et al., 2014).

In accordance with different ground types within the water area of the lake, we marked out three habitats (Fig. 1). In the northern shallow part and in the central deep part, the bottom is covered with thick silt deposits (station 1). In the places where stams flow into the lake, its bottom is covered with coarse sand sediments (station 2). In the southern and central part of the lake, grounds are represented by silted boulders, fine gravel, and pebble (station 3). Zones with different ground types were mapped with reference to the coordinates via GPS. The area occupied by each of the three habitats was then calculated based on Google Earth satellite imagery (https://www.google.ru/maps) using the Image J 1.46 software.

\section{Sampling}

The emergence of chironomid adults was estimated using semi-immersed conical mesh traps (Rosenberg 


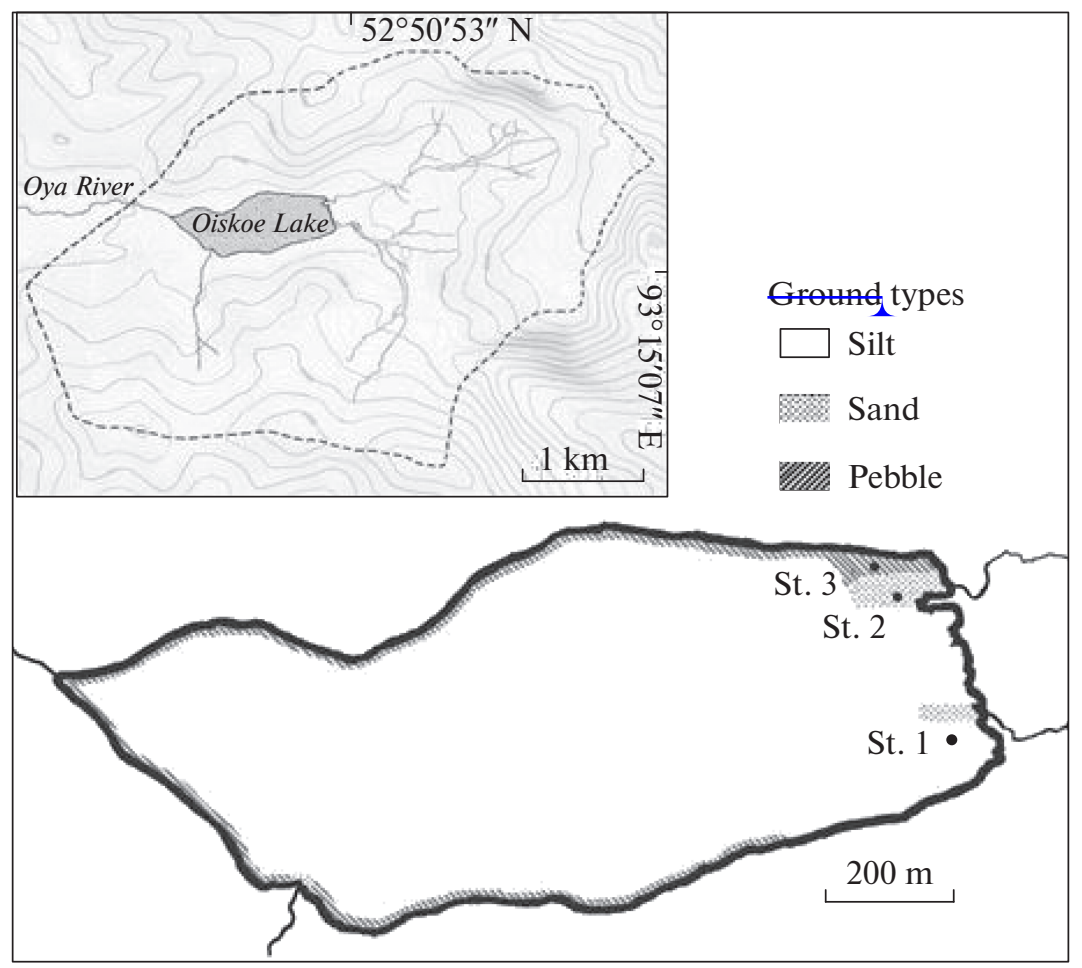

Fig. 1. Region of works and scheme of Oiskoe Lake with trap-installation stations. The dotted line marks the boundary of the valley territory as the zone to which chironomid adults expand.

et al, 1980; Demina et al., 2009) equipped with a modified removable accumulating collector for adults that emerged. The traps were fixed with weights on the bottom and equipped with elastic snells and a plastic float, which allowed them to maintain a vertical orientation under wind and waves. The area of an underwater trap cone was $0.28 \mathrm{~m}^{2}$ and its height was $0.5 \mathrm{~m}$.

In total, six traps were installed in the littoral zone (at depths of up to $1 \mathrm{~m}$ ) of the three stations (Fig. 1). The counts of emerging chironomid adults were made using traps in 2012-2014 from the middle of June to the last 10 days of August in six stages that lasted 614 days each: June 15-20, 2012; August 16-29, 2012; June 16-21, 2013; July 21-28, 2013; July 4-15, 2014; and August 2-13 2014. The total time of trap installation was 58 days. Winged adults were taken from traps every 2 days. When samples were taken, a removable collector was replaced by a new one; chironomid adults were taken out at laboratory conditions, which made it possible to avoid losses during manipulations. The average number of adults that flew from traps installed in a given station was estimated.

The collected specimens were sorted by morphologically similar groups that took account of the size, sex, and visually distinguishable taxonomic characteristics and were counted and weighed. In total, eight morphological groups were marked out. Weighting was performed by a HP-200 analytical balance (A\&D, Japan) with a discreteness of mass determination of up to $0.1 \mathrm{mg}$. The average values of wet weight of an individual were estimated for each morphological group and then were used to calculate the contribution to the total biomass of individual taxa. Then the samples were preserved in $80 \%$ ethanol to establish the species identity.

Over 2012, a part of adult specimens of the dominant species caught with the mesh traps was selected for biochemical analyzes. In the same growing season, samples of benthic chironomid larvae were taken at stations 2 and 3 using a Petersen dredger. Larvae taken from seil samples were placed in filtered lake water for a day for the release of the intestine. Before weighing, excess moisture was removed from the surface of larvae bodies with filter paper. The samples for determining the fatty acid (FA) content and moisture were formed from several individuals of larvae or adults from morphologically similar groups, the weighed mass of which was within $10-80 \mathrm{mg}$ wet weight, and then they were weighed with an accuracy of $0.1 \mathrm{mg}$. The samples for determining the FA content were placed in a chloroform-methanol mixture, and then they and the samples for measurement of moisture were stored at $-20^{\circ} \mathrm{C}$ until further processing at the laboratory.

The species identity of mass chironomid species was identified in a laboratory based on preparations of male genitalia (Opredelitel' nasekomykh Evropeiskoi 


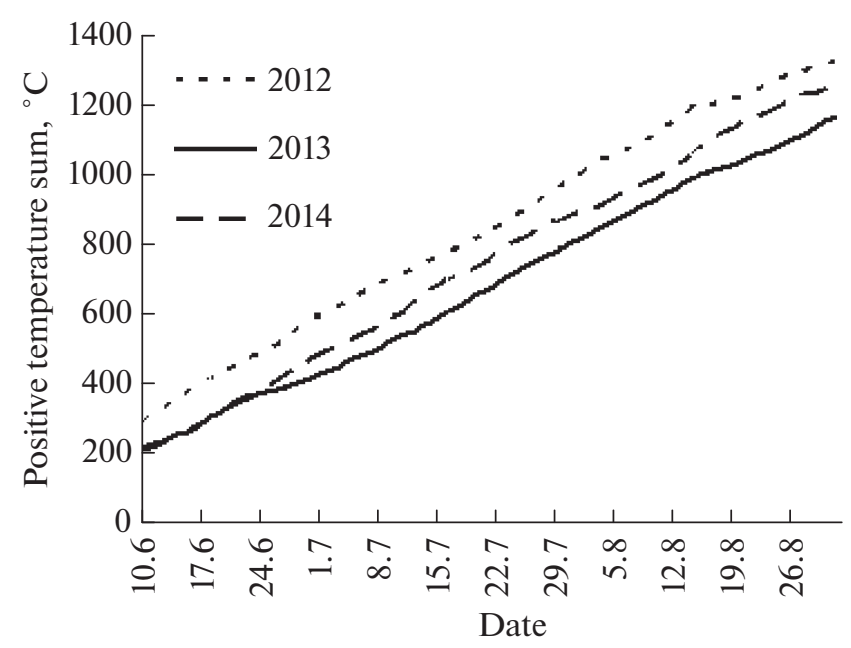

Fig. 2. Dynamics of positive temperature sum in the region of studies in summer 2012-2014 (the calculations were made based on the air temperature data obtained at the Olenya Rechka Meteorological Station, Roshydromet, http://rp5.ru).

chasti SSSR, 1969; Opredelitel' nasekomykh Dal'nego Vostoka Rossii, 1999).

\section{Calculation of Daily and Annual Emergence per Unit of Water and Land Area}

The calculations were made with consideration for the following factors. It is known that the intensity of the emergence of amphibiotic insects may largely vary during a growing season; in addition, the start and duration of emergence peaks may significantly vary in adults-depending on weather conditions in individual growing seasons (Lundstrom et al., 2010). In mountain ecosystems, as well as in ecosystems of temperate and cold climate, the key factor that determines the start of the mass emergence of amphibiotic insects is a seasonal rise in water temperature (Fureder et al., 2005). It is known that water temperature in mountain lakes in the open water period is significantly correlated with air temperature (Livingstone and Lotter, 1998). Due to the lack of long-teem reliable measurements of water temperatures in the lake, we used data on air temperature as a proxy of the water temperature dynamics. In order to determine the seasonal dynamics of the emergence of chironomids with consideration for measurements for different growing seasons, we used the model where the sum of positive air temperatures from the beginning of a season was used as an indicator of the time of the growing season. The calculations were made using the data on air temperatures obtained from the Olenya Rechka Meteorological Station (Roshydromet, http://rp5.ru), which is located in the studied area (4 km seuth-to the south from the Oiskoe Lake, $\left.52^{\circ} 50^{\prime} \mathrm{N}, 93^{\circ} 15^{\prime} \mathrm{E}\right)$ at the same altitude (1400 $\mathrm{m}$ above sea level) (Fig. 2). Positive val- ues were summed up in the series of average daily values of air temperature in 2012, 2013, and 2014. Therefore, a corresponding value of the positive temperature sum was obtained for each date of the counts of the emergence in chirenomids.

According to the observations in 2012-2014, the emergence of chironomids took place at the interval of the positive temperature sum of $309-1328^{\circ} \mathrm{C}$. In 2012-2014, this interval lasted 81-87 days in the studied area (on average, 83 days), and then there was not an increase in the positive temperature sum. Thus, the duration of the emergence of chironomids in the growing season was taken to be 83 days. The daily values of the emergence $\left(\mathrm{mg} \cdot \mathrm{m}^{2} \cdot \mathrm{day}^{-1}\right)$ were estimated for each date of the counts based on the biomass of chironomids caught with traps. The values of the emergence for different dates and different years were ranked by the indicators of temperature separately for each station. This yielded the graphs of the emergence intensity dynamics in chironomids during the growing season depending on a positive temperature sum for a given day. The values of the emergence were calculated as the averages of nearby values for the dates corresponding to the indicators of temperature sums when counts were not made.

The specific emergence ( $\mathrm{mg}$ wet weight $\cdot \mathrm{m}^{2}$ water area) for the growing season (a year) was estimated for each station and for all dominant species as a sum of all values of the daily emergence for the model period ( 83 days). The average specific emergence from the lake water area for a year was estimated taking account for the share of different habitats in the total area of the pond.

The total annual biomass flux from the water area resulting from the emergence of chironomids was calculated as a product of the value of the specific emergence from the water area and the lake area. The land area, for which the biomass flux was calculated, was estimated in the ImageJ 1.46 graphical editor using the Google Earth satellite imagery (https://www.google.ru/maps) and OpenStreetMap relief maps (https://www.openstreetmap.org). It is known that the average distance of the expansion of chironomid adults from the places of emergence is $13.3 \mathrm{~m}$ for $50 \%$ of individuals in a population; however, there are data on the maximum distance, which is $17 \mathrm{~km}$ (Muehlbauer et al., 2014). The shoreline band with a width of $15 \mathrm{~m}$ was taken by us into account as the minimum land area for which the biomass flux from the lake water area was calculated. The maximum land area was determined based on the assumption that the mountain ridges (the watershed $>1600$ above sea level) that border the lake valley are a natural boundary for the expansion of adults from the places of emergence. The boundaries of the valley were taken into account as the watershed line that goes through the upper relief points around the lake (Fig. 1). The areas covered by the emergence from the streams and 
Oi River were deduced from the land area. The biomass flux to the land was calculated as the ratio of the annual biomass flux from the entire water lake area to the covered land area.

The annual PUFA flux from a water area unit $\left(\mathrm{mg} \cdot \mathrm{m}^{2}\right.$ water area) was calculated as a product of the average specific emergence from a water area unit and the average summary content of EPA and DHA in the biomass of adults ( $\mathrm{mg} \cdot \mathrm{g}$ wet weight). In order to calculate the PUFA flux per land area unit, the annual biomass flux to the land was multiplied by the average PUFA content in the biomass of adults.

\section{Biochemical Analyses of Samples}

Moisture of the biomass of larvae and adults was determined at the laboratory by drying the samples up to a constant weight at $75^{\circ} \mathrm{C}$.

Analysis of fatty acids was described in detail in the works (Sushchik et al., 2013; Gladyshev et al., 2014). Lipids were extracted with chloroform and methanol in a ratio of $2: 1$, and then FAs of total lipids were methylated in a $85^{\circ} \mathrm{C}$. Methyl esters were analyzed by gas chromatography with a mass spectrometric detector (Model 6890/5975C, Agilent Technologies, United States) equipped with a HP-FFAP capillary column at the ionization energy of the detector of $70 \mathrm{eV}$ and scanning in the range of 45450 atomic units. The peaks of fatty acid methyl esters were identified based on the mass spectra obtained. The quantitative content of fatty acids in the biomass was determined based on the peak value of the internal standard (nonadecanoic acid (Sigma-Aldrich United States)), the fixed amount of which was added to the samples before the extraction of lipids.

\section{Statistical Analysis}

The nonparametric Mann-Whitney $U$-test was used to determine the reliability of differences between the average values of the FA content in the chironomid biomass; the differences were considered reliable at $p$ $<0.05$. The calculations were made using the Statistica-9 standard software package (StatSoft, United States).

\section{RESULTS}

The valley of the Oiskoe Lake is a zone with an area of $13258880 \mathrm{~m}^{2}$ isolated by mountain ridges in the center of which the lake is located (Fig. 1). The area occupied by the lake and the territory covered by the emergence of chironomids from the streams was deduced from the area of this zone. Thus, the maximum land area, to which chironomid adults can expand from the Oiskoe Lake, was $12172860 \mathrm{~m}^{2}$. The minimum land area used in the estimates of the bio- mass and PUFA fluxes brought with the chironomid emergence was $40671 \mathrm{~m}^{2}$.

The greater part of the lake bottom $(92 \%)$ was occupied by silted grounds with an area of $482110 \mathrm{~m}^{2}$ (Fig. 1). The areas with pebbly and sandy grounds were 27684 and $12327 \mathrm{~m}^{2}$, respectively.

Over the entire period of studies, representatives of 13 genera and 18 chironomid species were found in the traps. Table 1 presents the emergence intensity for adults of 11 species, which are quantitatively significant in the total emergence. The dominant chironomid species which emerged at the stations with silty and sandy grounds were Dicrotendipes nervosus (up to $40 \%$ of the total biomass) and Paratanytarsus siderophila (up to $24 \%$ ). In the pebbly areas, the maximum values of the emergence were noted for Tanytarsus pseudolestagei $(21 \%)$ (Table 1).

The seasonal dynamics of the emergence of chironomid adults on silty and sandy-seils were similar, with the most pronounced peak at the beginning of the growing season, $31.9 \mathrm{mg} \mathrm{m}^{-2}$ day $^{-1}$ and $45.3 \mathrm{mg} \mathrm{m}^{-2}$ day $^{-1}$ for stations 1 and 2, respectively. (Fig. 3). This peak was mainly due to the emergence of two dominant species, $D$. nervosus and $P$. siderophila. The second peak of the emergence corresponded to the interval of the positive temperature sum of $700-800^{\circ} \mathrm{C}$ and was observed during July; the main contribution was made by the species Orthocladius thienemanni and T. pseudolestagei (Fig. 3). The third peak that occurred at the end of the growing season was determined by the emergence of the species $P$. siderophila and Protanypus pseudomorio. In the pebbly grounds (station 3), only one peak of the emergence $\left(40.3 \mathrm{mg} \mathrm{m}^{-2}\right.$ day $\left.^{-1}\right)$ was observed in the studied period of 2012-2013 in the middle of the growing season at the interval of the positive temperature sum of $600-900^{\circ} \mathrm{C}$ (Fig. 3).

The minimum observed value of the specific annual emergence of chironomids corresponded to the pebbly ground of the shoreline zone (Table 1). The silty frounds of the littoral and deepwater areas were characterized by the value of the annual emergence. The maximum annual emergence of chironomids corresponded to the sandy grounds and was 2.3 times greater than the biomass flux from the pebbly ground (Table 1$)$. The average annual emergence for the water area, which was calculated taking account ef-the quantitative contribution of different greund types to the total lake area, was $415.05 \mathrm{mg}$ wet weight $\mathrm{m}^{-2}$.

The levels (the percentage of the total FA content) of quantitatively significant FAs in the lipids of the biomass of chironomid larvae and adults from the Oiskoe Lake are presented in Table 2. The dominant acids in the biomass of larvae were 16:0, 18:2n-6 and 18:1n9 and those in the biomass of adults were 20:5n-3, 16:0, and 18:2n-6. The average levels of the acids 12:0, i15:0, ai15:0, 16:1n-9, 16:1n-6, i17:0, 17:0, and 20:0 
Table 1. Annual emergence ( $\mathrm{mg}$ wet weight $\cdot \mathrm{m}^{2}$ water area) in the dominant ehirenemid species of the Chironomidae family from Oiskoe Lake (the Western Sayan, Southern Siberia, 2012-2014) for different types and average value for the water area ( \pm standard error).

\begin{tabular}{l|r|r|c|c}
\hline \multicolumn{1}{c|}{ Species } & \multicolumn{2}{c|}{ Station (ground type) } & $\begin{array}{c}\text { Average emergence } \\
\text { for the water area }\end{array}$ \\
\cline { 2 - 5 } & 1 (silt) & 2 (sand) & 3 (pebble) & $n=3$ \\
\hline Polypedilum scalaenum (Staeger, 1803) & 0.00 & 34.47 & 2.24 & $12.23 \pm 11.13$ \\
Dicrotendipes nervosus (Schrank, 1839) & 165.47 & 218.16 & 50.04 & $144.56 \pm 49.65$ \\
Tanytarsus pseudolestagei (Shilova, 1976) & 22.88 & 23.67 & 58.18 & $34.91 \pm 11.64$ \\
Micropsectra praecox (Wiedemann in Meigen, 1818) & 38.33 & 55.13 & 32.18 & $41.88 \pm 6.86$ \\
Paratanytarsus siderophila (Zvereva, 1950) & 99.21 & 113.05 & 2.65 & $71.63 \pm 34.72$ \\
Chironomus nigrifrons Linevitsh et Erbaeva, 1971 & 3.49 & 19.15 & 0.00 & $7.55 \pm 5.89$ \\
Protanypus pseudomorio Makarchenko, 1982 & 23.94 & 30.11 & 0.00 & $18.02 \pm 9.18$ \\
Corynoneura celeripes Winnertz, 1852 & 0.00 & 17.08 & 0.00 & $5.69 \pm 5.69$ \\
Cricotopus festivellus (Kieffer, 1906) & 3.49 & 18.25 & 35.99 & $19.24 \pm 9.40$ \\
Orthocladius thienemanni Kieffer, 1906 & 17.53 & 2.67 & 44.22 & $21.48 \pm 12.16$ \\
Acricotopus lucens (Zetterstedt, 1850) & 8.11 & 8.56 & 12.96 & $9.88 \pm 1.55$ \\
Others & 35.96 & 80.29 & 26.47 & $47.57 \pm 16.59$ \\
Total & 418.41 & 620.58 & 264.93 & $434.64 \pm 102.99$ \\
\hline
\end{tabular}

were reliably, lower in larvae; in turn, adults were characterized by reliably higher values of polyunsaturated fatty acids (PUFAs), namely 18:3n-3 and 20:5n-3 (Table 2). The average moisture content in larvae and adults was 75.8 and $64.5 \%$ wet weight, respectively. The total FA content per unit of the wet and dry biomass of chironomid adults was 2-3 times larger than that in the biomass of larvae. The quantitative content of essential EPA (per unit of wet or dry weight) was also significantly higher in adults (Table 2). The quantitative and percentage content of DHA in both larvae and adults was negligible. With the total content of EPA and DHA in the biomass of chironomid adults (4.22 mg g wet weight) and the average emergence for the water area ( $415.05 \mathrm{mg}$ wet weight $\mathrm{m}^{-2}$ year $^{-1}$ ) being taken into account, the PUFA flux per water area unit was $1.752 \mathrm{mg} \mathrm{m}^{-2}$ year $^{-1}$. The calculations of the annual biomass fluxes and the total amount of EPA + DHA that resulted from the emergence of chironomid adults per land area unit are shown in Table 3. The maximum and minimum values of the fluxes were determined by the possible distance of the expansion of chironomid adults from the place of emergence (correspondingly, by the land area taken into account in the calculations) and differed for the studied region almost 250 times.

\section{DISCUSSION}

The available literature gives data on the quantitative daily or annual emergence of amphibiotic insects in dry-weight units per water-area unit. With consideration for the average length of the growing season of
83 days and moisture of the adults biomass of $64.5 \%$, the average emergence intensity in the chironomids from the-Oiskoe Lake was $1.8 \pm 0.45,2.9 \pm 0.67$, and $1.2 \pm 0.61 \mathrm{mg}$ dry weight $\mathrm{m}^{-2} \mathrm{day}^{-1}$ for the silty, sandy, and pebbly grounds, respectively. These values were close to the daily values of the chironomid emergence, which were observed at the streams of the Rhine River, on average, $0.23 \mathrm{mg}$ dry weight $\cdot \mathrm{m}^{-2} \cdot \mathrm{day}^{-1}$ (Krell et al., 2015). However, the daily emergence of chironomids from the water area of the studied mountain lake was 2.5 and 9 times smaller than that from the streams of the Appalachian Mountain Range (Davis et al., 2011) and mountain river in the northeast of Italy (Paetzold and Tockner, 2005).

Obviously, the total annual emergence of amphibiotic insects is not only dependent on the intensity of daily emergence, but is also determined by the duration of the growing season. Therefore, several seasonal peaks of the emergence of amphibiotic insects may be observed in the areas with warmer climates (Rundio and Lindley, 2012). Athe Oiskoe Lake, there was only one pronounced seasonal peak of emergence for most chironomid species (Fig. 3), which could be due to the relatively short growing season. The annual chironomid emergence from the studied mountain lake, which averaged $0.15 \mathrm{~g}$ dry weight $\mathrm{m}^{-2}$, was compared with the values obtained for water ecosystems of cold and temperate climates. The annual emergence from the-Oiskoe Lake is comparable with the chironomid emergence from wetlands of Sweden and salty marshes in the northeastern United States (0.3 and $0.2 \mathrm{~g} \mathrm{~m}^{-2}$ year $^{-1}$, respectively; the calculations were made taking account of the dry weight of ene individ- 
ual, which is $\sim 150 \mu \mathrm{g}$ ) (Stagliano et al., 1998; MacKenzie, 2005; Lundstrom et al., 2010), as well as from a floodplain lake of the Volga River Basin $\left(0.21 \mathrm{~g} \mathrm{~m}^{-2}\right.$ year $^{-1}$ ) (Demina et al., 2013). However, the average value for the mountain lake that we obtained was close only to the minimum value of the chironomid emergence $\left(0.17-3.7 \mathrm{~g} \mathrm{~m}^{-2}\right.$ year $\left.^{-1}\right)$ from the-Myvatn eutrophic lake, which is located in the geothermal area of Iceland and features favorable conditions for the intensive growth and development of benthic chironomids (Dreyer et al., 2015). In addition, the values of the annual chironomid emergence, which were determined for many other water systems of temperate and cold climates, were 1-2 orders of magnitude higher than the value of the emergence obtained in our work (Paasivirta et al, 1988;; Leeper and Taylor, 1998; Stagliano et al., 1998; Rolauffs et al., 2001). Thus, the mountain oligotrophic lake was notable for one of the lowest values of the annual emergence of amphibiotic insects compared to other studied ponds and watercourses.

It is known that the emergence of amphibiotic insects is about $24 \%$ of the annual secondary production of benthic larvae (Huryn and Wallace, 2000). The annual benthos secondary production at the Oiskoe Lake averaged $3.12 \mathrm{~g}$ wet weight $\mathrm{m}^{-2}$ (Zuev et al., 2012), and the chironomid production accounted for about $70 \%$ of the total benthos production (S.P. Shulepina, a personal repert). Therefore, the potential annual emergence of chironomids from Oiskoe Lake can be estimated at $0.52 \mathrm{~g}$ wet weight $\mathrm{m}^{-2}$. This estimate is in good agreement with the value of the average emergence for the water area, which was measured using traps (Table 1).

It is known that the flux of the biomass of emerging insects per land area unit will reach its maximum value in the territory immediately adjacent to the emergence site, where no less than a half of individuals of the chironomid population stay (Muehlbauer et al., 2014). However, the literature contains information on the range of chironomid expansion that reaches $17 \mathrm{~km}$ from the emergence site (Muehlbauer et al., 2014). Since the distance of watersheds from the water area of Oiskoe Lake does not surpass $2.5 \mathrm{~km}$, the entire territory of the valley is potentially reachable for chironomid adults during their expansion. The largest and least possible values of the fluxes of organic matter and PUFAs to the land differed by more than two orders of magnitude (Table 3) and indicated the key role of the shoreline zone as a source of secondary products-for terrestrial consumers of the studied mountain landscape.

The fatty acid composition of the collected larvae of chironomids, among which D. nervosus and T. pseudolestagei were the dominant species (Zuev et al., 2012), was characterized by the noticeable contribution of acids that are bacterial markers (i15:0, ai15:0, i17:0, a17:0, and 17:1n-8), the total amount of which
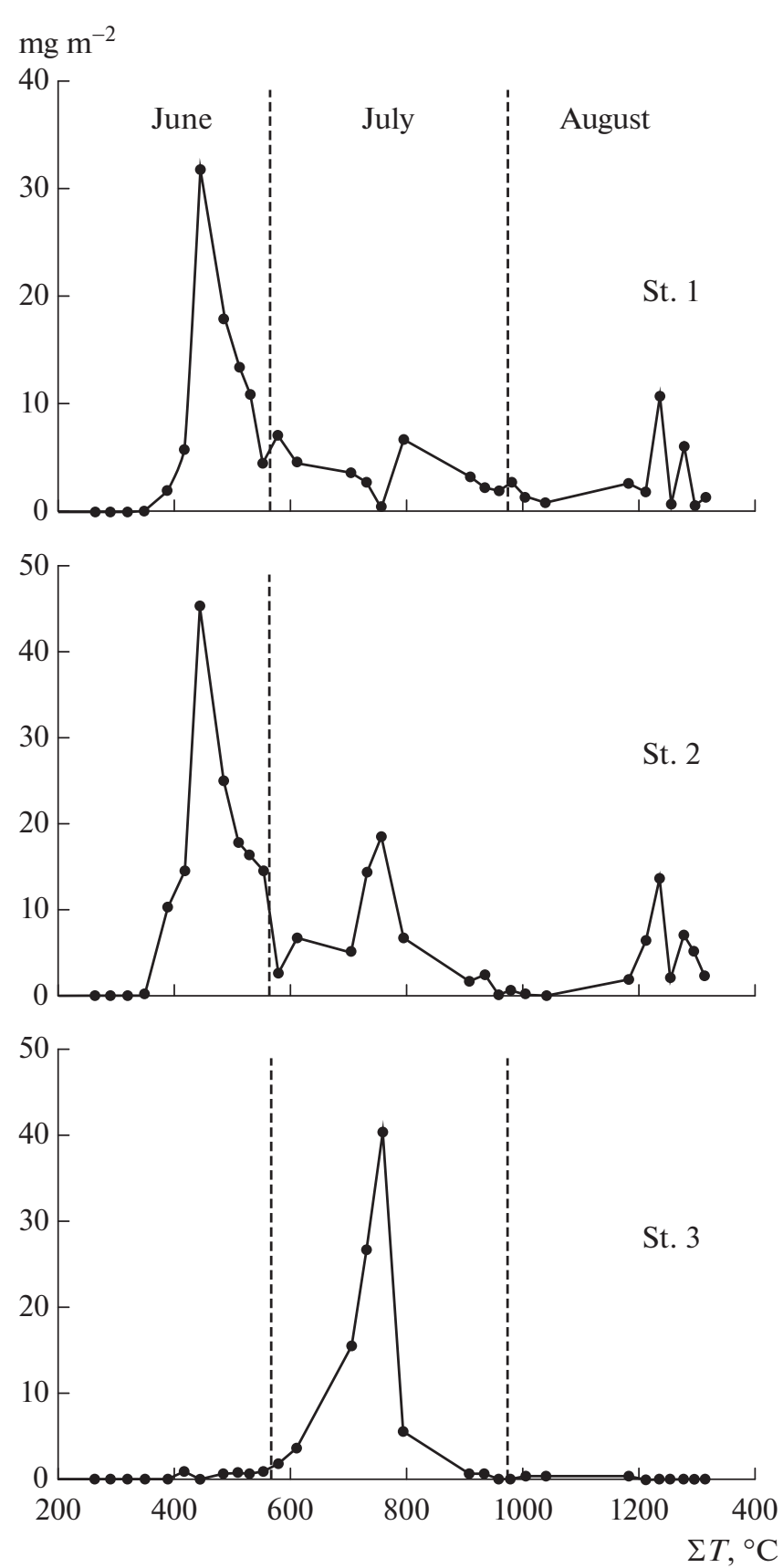

Fig. 3. Daily emergence of chironomid adults (mg wet weight $\cdot \mathrm{m}^{-2} \mathrm{day}^{-1}$ ) at the stations of the Oiskoe Lake depending on the observed positive temperature sum, 2012-2014.

was $5 \%$. Therefore, detritus and particles of suspended organic matter made up a significant part of the feeding in the chironomids which lived in the lake, where seils were mainly represented by silts. The biomass of chironomid larvae from Oiskoe Lake were noted to have the highest content of linoleic acid (18:2n-6) compared to other chironomids of freshwater and brackish habitats (Bell et al., 1994; Descroix 
Table 2. Fatty acid composition (mean \pm standard error, $\%$ of the total amount of fatty acids (FAs), mo/g wet or dry weight, $\mathrm{n}$ is the number of samples) in the Chironomidae larvae and adults collected in June-August 2012 at Oiskoe Lake (the Western Sayan, Southern Siberia). The reliability of the-distinen between mean vales was determined by the MannWhitney $U$-test. The reliably vale of $p$ are bolded.

\begin{tabular}{|c|c|c|c|c|}
\hline FAs & larvae & adults & \multirow{2}{*}{$U$} & \multirow{2}{*}{$p$} \\
\hline$\%$ & $n=4$ & $n=6$ & & \\
\hline $12: 0$ & $3.2 \pm 0.8$ & $0.6 \pm 0.1$ & 1.0 & 0.0252 \\
\hline $14: 0$ & $3.3 \pm 0.7$ & $2.2 \pm 0.8$ & 5.0 & 0.1658 \\
\hline $14: 1 n-5$ & $0.2 \pm 0.1$ & $0.7 \pm 0.5$ & 10.0 & 0.7491 \\
\hline i15:0 & $1.9 \pm 0.2$ & $0.4 \pm 0.1$ & 0.0 & 0.0142 \\
\hline ai15:0 & $1.1 \pm 0.3$ & $0.2 \pm 0.1$ & 0.0 & 0.0142 \\
\hline $15: 0$ & $0.9 \pm 0.2$ & $0.6 \pm 0.1$ & 5.0 & 0.1658 \\
\hline $16: 0$ & $18.8 \pm 1.4$ & $16.2 \pm 0.6$ & 5.0 & 0.1658 \\
\hline $16: 1 n-9$ & $1.0 \pm 0.1$ & $0.4 \pm 0.1$ & 0.0 & 0.0142 \\
\hline $16: 1 n-7$ & $8.6 \pm 0.5$ & $12.2 \pm 1.4$ & 4.0 & 0.1098 \\
\hline $16: 1 n-6$ & $1.3 \pm 0.1$ & $0.5 \pm 0.1$ & 0.0 & 0.0142 \\
\hline i17:0 & $0.4 \pm 0.0$ & $0.1 \pm 0.0$ & 0.0 & 0.0142 \\
\hline ai17:0 & $0.3 \pm 0.1$ & $0.2 \pm 0.0$ & 8.0 & 0.4555 \\
\hline $16: 2 n-4$ & $0.5 \pm 0.1$ & $0.7 \pm 0.3$ & 10.0 & 0.7491 \\
\hline 17:0 & $1.8 \pm 0.1$ & $1.0 \pm 0.2$ & 0.0 & 0.0142 \\
\hline $17: 1 n-8$ & $1.3 \pm 0.1$ & $0.7 \pm 0.2$ & 3.0 & 0.0700 \\
\hline $18: 0$ & $8.3 \pm 1.0$ & $5.5 \pm 0.6$ & 3.0 & 0.0700 \\
\hline $18: 1 n-9$ & $10.2 \pm 0.8$ & $9.2 \pm 1.1$ & 7.0 & 0.3374 \\
\hline $18: 1 n-7$ & $3.9 \pm 0.3$ & $5.9 \pm 1.3$ & 10.0 & 0.7491 \\
\hline $18: 2 n-6$ & $13.9 \pm 1.4$ & $12.4 \pm 1.6$ & 9.0 & 0.5940 \\
\hline $18: 3 n-6$ & $0.5 \pm 0.1$ & $0.5 \pm 0.0$ & 10.0 & 0.7491 \\
\hline $18: 3 n-3$ & $2.9 \pm 0.5$ & $5.0 \pm 0.7$ & 2.0 & 0.0428 \\
\hline $18: 4 n-3$ & $0.6 \pm 0.0$ & $0.9 \pm 0.4$ & 9.0 & 0.5940 \\
\hline 20:0 & $1.4 \pm 0.2$ & $0.9 \pm 0.1$ & 2.0 & 0.0428 \\
\hline $20: 1 n-9$ & $0.3 \pm 0.1$ & $0.2 \pm 0.1$ & 8.0 & 0.4555 \\
\hline $20: 4 n-6$ & $2.8 \pm 0.2$ & $3.4 \pm 0.7$ & 4.0 & 0.1098 \\
\hline $20: 5 n-3$ & $7.8 \pm 0.1$ & $17.2 \pm 0.8$ & 0.0 & 0.0142 \\
\hline $22: 0$ & $0.7 \pm 0.1$ & $0.4 \pm 0.0$ & 3.0 & 0.0700 \\
\hline $22: 6 n-3$ & $0.1 \pm 0.1$ & $0.1 \pm 0.0$ & 9.0 & 0.5940 \\
\hline $\mathrm{mg}$ g g wet weight & $n=4$ & $n=4$ & & \\
\hline $20: 5 n-3$ & $0.58 \pm \theta .1$ & $4.21 \pm 0.99$ & 0.0 & 0.0304 \\
\hline $22: 6 n-3$ & $0.01 \pm \theta .0$ & $0.01 \pm 0.00$ & 4.5 & 0.3865 \\
\hline Total amount of FAs & $7.40 \pm 1.5$ & $23.10 \pm 4.39$ & 0.0 & 0.0304 \\
\hline $\mathrm{mg} \cdot \mathrm{g}$ dry weight & $n=4$ & $n=4$ & & \\
\hline $20: 5 n-3$ & $2.41 \pm 0.50$ & $11.87 \pm 2.80$ & 0.0 & 0.0304 \\
\hline $22: 6 n-3$ & $0.03 \pm 0.30$ & $0.03 \pm 0.01$ & 4.5 & 0.3865 \\
\hline Total amount of FAs & $30.59 \pm 6.16$ & $65.07 \pm 12.37$ & 1.0 & 0.0606 \\
\hline
\end{tabular}


Table 3. Fluxes of biomass and the of EPA + DHA via the emergence of chironomid adults from Oiskoe Lake to the land area of the Western Sayan (Southern Siberia, 2012-2014)

\begin{tabular}{|c|c|c|}
\hline Parameters & Maximum expansion area* & Maximum expansion area** \\
\hline Biomass flux from the entire lake water area, $\mathrm{g}_{\text {year }}{ }^{-1}$ & \multicolumn{2}{|c|}{216705} \\
\hline $\mathrm{EPA}+\mathrm{DHA}$ flux from the entire lake water area, $\mathrm{g} \mathrm{year}^{-1}$ & \multicolumn{2}{|c|}{914.495} \\
\hline Land area taken into account in the estimates, $\mathrm{m}^{2}$ & 40671.22 & 12172860.26 \\
\hline Biomass flux, g wet weight $\mathrm{m}^{-2}$ land area year ${ }^{-1}$ & 5.328 & 0.018 \\
\hline $\mathrm{EPA}+\mathrm{DHA}$ flux, $\mathrm{mg} \mathrm{m}^{-2}$ land area year ${ }^{-1}$ & 22.282 & 0.076 \\
\hline
\end{tabular}

\footnotetext{
* The estimate was made based on the average distance of expansion of chironomids that is $15 \mathrm{~m}$ from the lake shoreline.

** The estimate was made based on the largest possible distance of expansion of chironomids that is determined by the size of the mountain valley.
}

et al., 2010.; Makhutova et al, 2011; Sauvanet et al., 2013.; Zinchenko et al., 2014). This PUFA is absolutely essential for most animals, including insects of the Diptera order (Stanley-Samuelson et al., 1988) and could be consumed by the larvae of the-Oiskoe Lake with detritus formed by the decomposition of higher aquatic vegetation, or by the consumption of living tissues of higher plants. In the Oiskoe mountain lake, which features an extended littoral, higher aquatic plants are major contributors to the gross primary production (Ivanova et al., 2014). Linoleic acid is synthesized and accumulated in many species of higher aquatic plants [Rozentsvet et al., 2002] and is used as a biomarker of this group of producers in some research the nutrition of thang et al., 2014). Periphyton green algae could be another possible source of linoleic acid in the diet of chironomid larvae, but their biomass was relatively low (Ivanova et al.).

Since the content of DHA in chironomids was very low (Table 2), a further comparative analysis of the content of essential PUFAs was performed only for the EPA. The content of essential EPA in chironomid larvae of the-Oiskoe Lake was 6-8 times lower than that in Cricotopus salinophilus and Prodiamesa olivacea (Makhutova et al., 2011; Zinchenko et al., 2014), but close to the values in the species of the Chironomus genus from different habitats (Goedkoop et al., 2000.; Makhutova et al., 2011; Zinchenko et al., 2014).

The information on the fatty acid composition in adults of the Chironomidae family is absent in the literature known to us, and the quantitative data on the content of EPA and DHA are limited to single measurements (Gladyshev et al., 2009). At the same time, it is obvious that, during metamorphosis, the chironomids of the-Oiskoe Lake experienced cardinal changes in the fatty acid composition that consisted of a significant increase in the levels of PUFAs, 18:3n-3, 20:5n3 , and 20:4n-6, at the expense of a decrease in the levels of saturated fatty acid levels, as well as acids-markers of bacteria, which were accompanied by the increase in the total content of FAs per biomass unit. It should be noted that, during the metamorphosis of the taxonomically close group of the Culicidae family, the relative accumulation of essential EPA and DHA was not observed in adults, although the fatty acid composition significantly changed (Gladyshev et al., 2011b; Sushchik et al., 2013). The total quantitative content of EPA + DHA in larvae and adults of several water-bug species of the Heteroptera order was also the same (Sushchik et al., 2014). It is possible that chironomids are a unique group of amphibiotic insects that are capable of significantly increasing the share of EPA + DHA in their biomass during metamorphosis.

The total content of EPA + DHA per mass unit at the adult stage was only measured in a small number of taxa of aquatic and amphibiotic insects. The average content of EPA in chironomid adults was almost twice as high as in adults of blood-sucking mosquitoes and dragonflies, but was close to that in adults of eorexids (the Heteroptera order) (Gladyshev et al., 2011a; Sushchik et al., 2013.; Sushchik et al., 2014).

According to the estimate made earlier, the average Biosphere's EPA + DHA flux from water to land via the emergence of amphibiotic insects is $\sim 40 \mathrm{mg} \mathrm{m}^{-2}$ water area year ${ }^{-1}$ (Gladyshev et al., 2009). The EPA + DHA flux per unit water area of the mountain lake via the emergence of the dominant insect group, which we measured, was 20 times lower than the average value for the Biosphere. However, in the cited work, the estimates of the average global flux were made using the data on the total emergence of all taxa without reference to specific landscapes, and, since the content of EPA and DHA in the biomass of adults was not known at that time, the estimates were made using average data obtained for adults of different taxa. Since the quantitative content of EPA and DHA in chironomid adults was much higher than in larvae, the latter factor could not be a cause of such a significant distinetion of the EPA and DHA flux in the specific system from the average global estimate. It is most likely that the very small value of the EPA and DHA flux from water to land, which was obtained in this study, is caused by the low productivity of the investigated mountain lake as well as by the short growing season in the studied mountain landscape. 
Currently there are only two researches in the available literature which directly measured the EPA and DHA fluxes from water to land via the emergence of certain taxa of amphibiotic insects in specific landscapes, namely, blood-sucking mosquitoes (the Culicidae family) in steppe and dragonflies (the Odonata order) in forest steppe (Gladyshev et al., 2011a, b). The annual EPA and DHA flux from the unit water area via the emergence of blood-sucking mosquitoes was more than twice as high as the EPA and DHA flux via to the emergence of chironomids. In turn, the EPA and DHA flux via the emergence of dragonflies was determined per unit land area and came to $6.9 \mathrm{mg} \mathrm{m}^{-2}$ year ${ }^{-1}$ (Gladyshev et al., 2011a). The value was more than 90 times higher than the EPA and DHA flux to land via the emergence of chironomids from the mountain lake, which was calculated with consideration for the entire area of the mountain valley; however, it was comparable with the EPA and DHA flux obtained for the shoreline band of the lake (Table 3).

\section{CONCLUSIONS}

Thus, the biomass flux via the emergence of chironomid adults from the unit area of the mountain oligotrophic lake proved to be among the lowest measurements made in specific landscapes for certain taxa of amphibiotic insects. At the same time, the measured value of the emergence corresponds to the zoobenthos productivity of this lake. The comparison of the fatty acid composition and content of EPA and DHA at different stages of development of chironomids, which was performed for the first time, revealed the unique capability of this amphibiotic group to accumulate significant amounts of essential EPA and DHA at the adult stage. However, despite the high content of EPA and DHA in emerging adults, the EPA and DHA flux from unit water area was several times lower than the average global estimates due to the low productivity of the lake.

The EPA and DHA flux per unit area of the mountain lake, which was calculated taking into consideration the maximum range of expansion in chironomids, was extremely small. It is possible that terrestrial omnivorous consumers of this landscape experience a shortage of EPA and DHA in food if they get food at a distance from the shoreline of the lake. However, in the shoreline part of the land area, the EPA and DHA flux per unit land area reached values comparable with more productive landscapes, which can stimulate terrestrial consumers to feeding in the shoreline band to enlarge the reserves of essential biochemical components.

\section{ACKNOWLEDGMENTS}

These studies were conducted with the assistance of the administration of the Ergaki Nature Park. We thank A.V. Ageev, K.V. Savenko, T.K. Savenko, and
N.V. Mikhalyuk for help in field works. This work was supported by the State Order of the Ministry of Education and Science of the Russian Federation to the Siberian Federal University to conduct research no. 6.1089.214/K and State Order within the Program of Fundamental Research of the Russian Federation Subject no. 51.1.1.

\section{REFERENCES}

Anishchenko, O.V., Glushchenko, L.A., Dubovskaya, O.P., Zuev, I.V., Ageev, A.V., and Ivanova, E.A., Morphometry and metal concentrations in water and bottom sediments of mountain lakes in Ergaki natural park, Western Sayan mountains, Water Resour., 2015, vol. 42, no. 5, pp. 670-682.

Bartels, P., Cucherousset, J., Steger, K., Eklov, P., Tranvik, L.J., and Hillebrand, H., Reciprocal subsidies between freshwater and terrestrial ecosystems structure consumer resource dynamics, Ecology, 2012, vol. 93, pp. 1173-1182.

Baxter, C.V., Fausch, K.D., and Saunders, W.C., Tangled webs: reciprocal flows of invertebrate prey link streams and riparian zones, Freshwater Biol., 2005, vol. 50, pp. 201-220.

Bell, J.G., Ghioni, C., and Sargent, J.R., Fatty acid compositions of 10 freshwater invertebrates which are natural food organisms of Atlantic salmon (Salmo salar): a comparison with commercial diets, Aquaculture, 1994, vol. 128 , pp. $301-313$.

Davis, J.M., Rosemond, A.D., and Small, G.E., Increasing donor ecosystem productivity decreases terrestrial consumer reliance on a stream resource subsidy, Oecologia, 2011, vol. 167, pp. 821-834.

Descroix, A., Bec, A., Bourdier, G., Sargos, D., Sauvanet, J., Misson, B., and Desvilettes, C., Fatty acids as biomarkers to indicate main carbon sources of four major invertebrate families in a large river (the Allier, France), Fundam. Appl. Limnol., 2010, vol. 177, pp. 39-55.

Djemina, I.V., Yermokhin, M.V., and Demin, A.G., Traps for quantitative estimation of adult amphibiotic insect emergence through boundary "water-air" in lentic aquatic systems, Povolzhsk. Ekol. Zh., 2009, no. 1, pp. 65-68.

Djemina, I.V., Yermokhin, M.V., and Polukonova, N.V., Structure and dynamics of matter and energy fluxes through the boundary "water-air" resulted from adult amphibiotic insect emergence in flood-plain lakes of the Volga basin, Izv. Sarat. Gos. Univ., Ser. Khim., Biol., Ekol., 2013, vol. 13, no. 3, pp. 85-93.

Dreyer, J., Hoekman, D., and Gratton, C., Lake-derived midges increase abundance of shoreline terrestrial arthropods via multiple trophic pathways, Oikos, 2012, vol. 121 , pp. 252-258.

Dreyer, J., Townsend, P.A., Hook III, J.C., Hoekman, D., Vander Zanden, M.J., and Gratton, C., Quantifying aquatic insect deposition from lake to land, Ecology, 2015, vol. 96, pp. 499-509.

Fontaneto, D., Tommaseo-Ponzetta, M., Galli, C., Rise, P., Glew, R.H., and Paoletti, M.G., Differences in fatty acid composition between aquatic and terres- 
trial insects used as food in human nutrition, Ecol. Food Nutr., 2011, vol. 50, pp. 351-367.

Fureder, L., Wallinger, M., and Burger, R., Longitudinal and seasonal pattern of insect emergence in alpine streams, Aquat. Ecol., 2005, vol. 39, pp. 67-78.

Gladyshev, M.I., Arts, M.T., and Sushchik, N.N., Preliminary estimates of the export of omega- 3 highly unsaturated fatty acids (EPA+DHA) from aquatic to terrestrial ecosystems, in Lipids in Aquatic Ecosystems, Arts, M.T., Brett, M.T., and Kainz, M., Eds., New York: Springer-Verlag, 2009, pp. 179-209.

Gladyshev, M.I., Kharitonov, A.Yu., Popova, O.N., Sushchik, N.N., Makhutova, O.N., and Kalacheva, G.S., Quantitative estimation of dragonfly role in transfer of essential polyunsaturated fatty acids from aquatic to terrestrial ecosystems, Dokl. Biochem. Biophys., 2011a, vol. 438 , no. 1 , pp. 141-143.

Gladyshev, M.I., Sushchik, N.N., Gubanenko, G.A., Kalachova, G.S., Rechkina, E.A., and Malyshevskaya, K.K., Effect of the way of cooking on contents of essential polyunsaturated fatty acids in filets of zander, Czech J. Food Sci., 2014, vol. 32, pp. 226-231.

Gladyshev, M.I., Sushchik, N.N., and Makhutova, O.N., Production of EPA and DHA in aquatic ecosystems and their transfer to the land, Prostaglandins Other Lipid Mediators, 2013, vol. 107, pp. 117-126.

Gladyshev, M.I., Sushchik, N.N., Yurchenko, Yu.A., Belevich, O.E., and Kalacheva, G.S., Differences in the fatty acid compositions of blood-sucking mosquito larvae and imagoes and the water-to-land export of essential acids, Dokl. Biol. Sci., 2011b, vol. 441, no. 1, pp. 385-388.

Goedkoop, W., Sonesten, L., Ahlgren, G., and Boberg, M., Fatty acids in profundal benthic invertebrates and their major food resources in Lake Erken, Sweden: seasonal variation and trophic indications, Can. J. Fish. Aquat. Sci., 2000, vol. 57, pp. 2267-2279.

Gratton, C. and Vander Zanden, M.J., Flux of aquatic insect productivity to land: comparison of lentic and lotic ecosystems, Ecology, 2009, vol. 90, pp. 26892699.

Huryn, A.D. and Wallace, J.B., Life history and production of stream insects, Annu. Rev. Entomol., 2000, vol. 45, pp. 83-110.

Ivanova, E.A., Anishchenko, O.V., Glushchenko, L.A., Gaevsky, N.A., and Kolmakov, V.I., Contribution of different groups of autotrophs to the primary production of mountain Lake Oiskoe, Contemp. Probl. Ecol., 2014, vol. 7, no. 4, pp. 397-409.

Krell, B., Röder, N., Link, M., Gergs, R., Entling, M.H., and Schäfer, R.B., Aquatic prey subsidies to riparian spiders in a stream with different land use types, Limnologica, 2015, vol. 51, pp. 1-7.

Lands, W.E.M., Human life: caught in the food web, in Lipids in Aquatic Ecosystems, Arts, M.T., Brett, M.T., and Kainz, M., Eds., New York: Springer-Verlag, 2009, pp. 327-354.

Leeper, D.A. and Taylor, B.E., Insect emergence from a South Carolina (USA) temporary wetland pond, with emphasis on the Chironomidae (Diptera), J. North Am. Benthol. Soc., 1998, vol. 17, pp. 54-72.
Livingstone, D.M. and Lotter, A.F., The relationship between air and water temperatures in lakes of the Swiss Plateau: a case study with palaeolimnological implications, J. Paleolimnol., 1998, vol. 19, pp. 181-198.

Lundstrom, J.O., Schafer, M.L., Petersson, E., Persson Vinnersten, T.Z., Landin, J., and Brodin, Y., Production of wetland Chironomidae (Diptera) and the effects of using Bacillus thuringiensis israelensis for mosquito control, Bull. Entomol. Res., 2010, vol. 100, pp. 117125 .

MacKenzie, R.A. and Kaster, J.L., Temporal and spatial patterns of insect emergence from a Lake Michigan coastal wetland, Wetlands, 2004, vol. 24, pp. 688-700.

MacKenzie, R.A., Spatial and temporal patterns in insect emergence from a southern Maine salt marsh, Am. Midl. Nat., 2005, vol. 153, pp. 257-269.

Maiolini, B., Lencioni, V., Boggero, A., Thaler, B., Lotter, A.F., and Rossaro, B., Zoobenthic communities of inlets and outlets of high altitude Alpine lakes, Hydrobiologia, 2006, vol. 562, pp. 217-229.

Makhutova, O.N., Sushchik, N.N., Gladyshev, M.I., Ageev, A.V., Pryanichnikova, E.G., and Kalachova, G.S., Is the fatty acid composition of freshwater zoobenthic invertebrates controlled by phylogenetic or trophic factors? Lipids, 2011, vol. 46, pp. 709-721.

Muehlbauer, J.D., Collins, S.F., Doyle, M.W., and Tockner, K., How wide is a stream? Spatial extent of the potential "stream signature" in terrestrial food webs using meta-analysis, Ecology, 2014, vol. 95, pp. 44-55.

Nakano, S. and Murakami, M., Reciprocal subsidies: dynamic interdependence between terrestrial and aquatic food webs, Proc. Nat. Acad. Sci. U.S.A., 2001, vol. 98, pp. 166-170.

Opredelitel' nasekomykh Dal'nego Vostoka Rossii, Tom. 6. Dvukrylye $i$ blokhi (Guide for Identification of the Insects of the Russian Far East, Vol. 6: Dipteran and Aphanipteran), Vladivostok: Dal'nauka, 1999, part 1.

Opredelitel' nasekomykh Evropeiskoi chasti SSSR. Tom 5. Dvukrylye, blokhi (Guide for Identification of Insects of European Part of the Soviet Union, Vol. 5: Dipteran and Aphanipteran Species), Leningrad: Nauka, 1969, part 1 .

Paasivirta, L., Lahti, T., and Peratie, T., Emergence phenology and ecology of aquatic and semi-terrestrial insects on a boreal raised bog in central Finland, Holarctic Ecol., 1988, vol. 11, pp. 96-105.

Paetzold, A. and Tockner, K., Effects of riparian arthropod predation on the biomass and abundance of aquatic insect emergence, J. Natl. Am. Benthol. Soc., 2005, vol. 24, pp. 395-402.

Reimer, J.P., Baerwald, E.F., and Barglay, R.M.R., Diet of hoary (Lasiurus cinereus) and silver-haired (Lasionycteris noctivagans) bats while migrating through Southwestern Alberta in late summer and autumn, Am. Midl. Nat., 2010, vol. 164, pp. 230-237.

Richardson, J.S., Zhang, Y., and Marczak, L.B., Resource subsidies across the land-freshwater interface and responses in recipient communities, River Res. Appl., 2010, vol. 26, pp. 55-66.

Rolauffs, P., Hering, D., and Lohse, S., Composition, invertebrate community, and productivity of a beaver 
dam in comparison to other stream habitat types, Hydrobiologia, 2001, vol. 459, pp. 201-212.

Rosenberg, D.M., Wiens, A.P., and Bilyj, B., Sampling emerging Chironomidae (Diptera) with submerged funnel traps in a new northern Canadian reservoir, Southern Indian Lake, Manitoba, Can. J. Fish. Aquat. Sci., 1980, vol. 37, pp. 927-936.

Rozentsvet, O.A., Saksonov, S.V., and Dembitsky, V.M., Hydrocarbons, fatty acids, and lipids of freshwater grasses of the Potamogetonaceae family, Biochemistry (Moscow), 2002, vol. 67, no. 3, pp. 351-356.

Rumpold, B.A. and Schluter, O.K., Nutritional composition and safety aspects of edible insects, Mol. Nutr. Food Res., 2013, vol. 57, pp. 802-823.

Rundio, D.E. and Lindley, S.T., Reciprocal fluxes of stream and riparian invertebrates in a coastal California basin with Mediterranean climate, Ecol. Res., 2012, vol. 27, pp. 539-550.

Sabo, J.L. and Power, M.E., River-watershed exchange: effects of riverine subsidies on riparian lizards and their terrestrial prey, Ecology, 2002, vol. 83, pp. 1860-1869.

Sauvanet, J., Bourdier, G., Jouve, L., Bec, A., and Desvilettes, C., Feeding of pike larvae (Esox lucius L.) in an alluvial river backwater: fatty acid as markers of two organic matter flows, Fundam. Appl. Limnol., 2013, vol. 183, pp. 337-350.

Scheibler, E.E., Roig-Junent, S.A., and Claps, M.C., Chironomid (Insecta: Diptera) assemblages along an Andean altitudinal gradient, Aquat. Biol., 2014, vol. 20, pp. 169-184.

Stagliano, D.M., Benke, A.C., and Anderson, D.H., Emergence of aquatic insects from 2 habitats in a small wetland of the southeastern USA: temporal patterns of numbers and biomass, J. North Am. Benthol. Soc., 1998, vol. 17, pp. 37-53.

Stanley-Samuelson, D.W., Jurenka, R.A., Cripps, C., Blomquist, G.J., and de Renobales, M., Fatty acids in insects: composition, metabolism, and biological sig- nificance, Arch. Insect Biochem. Physiol., 1988, vol. 9, pp. 1-33.

Stenroth, K., Polvi, L.E., Faltstrom, E., and Jonsson, M., Land-use effects on terrestrial consumers through changed size structure of aquatic insects, Freshwater Biol., 2015, vol. 60, pp. 136-149.

Sushchik, N.N., Comparison of fatty acid contents and composition in major lipid classes of larvae and adults of mosquitoes (Diptera: Culicidae) from a steppe region, Insect Sci., 2013, vol. 20, pp. 585-600.

Sushchik, N.N., Yurchenko, Y.A., Belevich, O.E., Kolmakova, A.A., Kalacheva, G.S., and Gladyshev, M.I., The role of water bugs (Heteroptera) as a potential source of essential polyunsaturated fatty acids for terrestrial consumers in steppe and forest-steppe, Dokl. Biochem. Biophys., 2014, vol. 459, no. 1, pp. 194-198.

Vander Zanden, M.J. and Gratton, C., Blowin' in the wind: reciprocal airborne carbon fluxes between lakes and land, Can. J. Fish. Aquat. Sci. 2011, vol. 68, pp. 170-182

Wang, S., Chu, T., Huang, D., Li B., and Wu, J., Incorporation of exotic Spartina alterniflora into diet of depositfeeding snails in the Yangtze river estuary salt marsh: stable isotope and fatty acid analyses ecosystems, Ecosystems, 2014, vol. 17, pp. 567-577.

Zinchenko, T.D., Gladyshev, M.I., Makhutova, O.N., Sushchik, N.N., Kalachova, G.S., and Golovatyuk, L.V., Saline rivers provide arid landscapes with a considerable amount of biochemically valuable production of chironomid (Diptera) larvae, Hydrobiologia , 2014, vol. 722, pp. 115-128.

Zuev, I.V., Dubovskaya, O.P., Ivanova, E.A., Glushchenko, L.A., Shulepina, S.P., and Ageev, A.V., Evaluation of the potential fish productivity of Lake Oiskoe (Ergaky Mountain Range, West Sayan) basing on food supply, Contemp. Probl. Ecol., 2012, vol. 5, no. 4, pp. $470-479$.

Translated by L. Solovyova

SPELL: 1. OK 